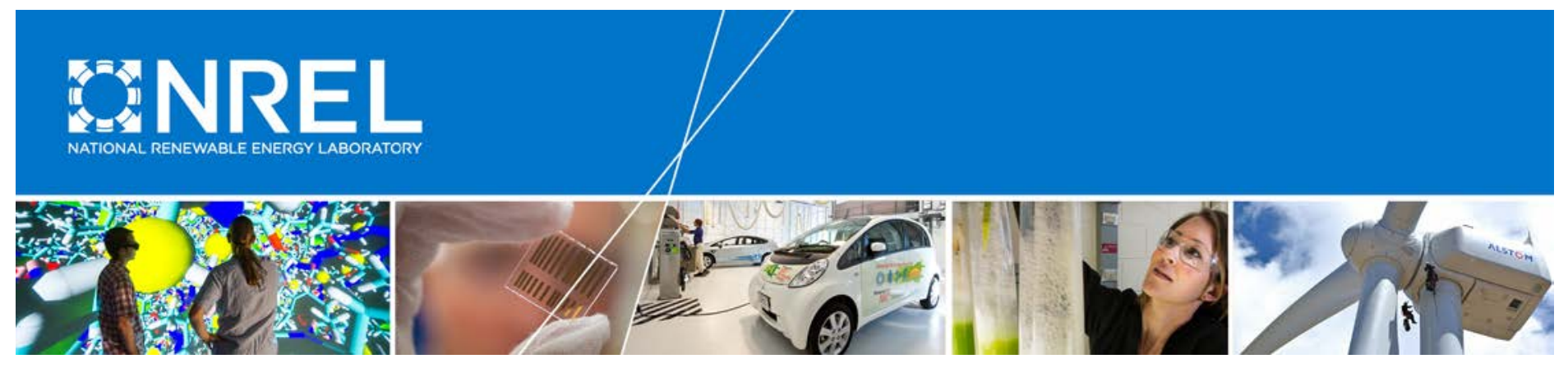

\title{
Planetary Load Sharing in Three-Point Mounted Wind Turbine Gearboxes: A Design and Test Comparison
}

Jonathan Keller and Yi Guo

National Renewable Energy Laboratory

Zhiwei Zhang

Romax InSight

Doug Lucas

The Timken Company

NREL is a national laboratory of the U.S. Department of Energy Office of Energy Efficiency \& Renewable Energy

Operated by the Alliance for Sustainable Energy, LLC

This report is available at no cost from the National Renewable Energy Laboratory (NREL) at www.nrel.gov/publications.

Technical Report

NREL/TP-5000-67394

April 2017

Contract No. DE-AC36-08G028308 


\section{Planetary Load Sharing in Three-Point Mounted Wind Turbine Gearboxes: A Design and Test Comparison}

Jonathan Keller and Yi Guo

National Renewable Energy Laboratory

Zhiwei Zhang

Romax InSight

Doug Lucas

The Timken Company

Prepared under Task No. WE16.5A02
NREL is a national laboratory of the U.S. Department of Energy Office of Energy Efficiency \& Renewable Energy Operated by the Alliance for Sustainable Energy, LLC

This report is available at no cost from the National Renewable Energy Laboratory (NREL) at www.nrel.gov/publications.

\section{Technical Report}

NREL/TP-5000-67394

April 2017

Contract No. DE-AC36-08GO28308
National Renewable Energy Laboratory 15013 Denver West Parkway

Golden, CO 80401

303-275-3000 • www.nrel.gov 


\section{NOTICE}

This report was prepared as an account of work sponsored by an agency of the United States government. Neither the United States government nor any agency thereof, nor any of their employees, makes any warranty, express or implied, or assumes any legal liability or responsibility for the accuracy, completeness, or usefulness of any information, apparatus, product, or process disclosed, or represents that its use would not infringe privately owned rights. Reference herein to any specific commercial product, process, or service by trade name, trademark, manufacturer, or otherwise does not necessarily constitute or imply its endorsement, recommendation, or favoring by the United States government or any agency thereof. The views and opinions of authors expressed herein do not necessarily state or reflect those of the United States government or any agency thereof.

This report is available at no cost from the National Renewable Energy Laboratory (NREL) at www.nrel.gov/publications.

Available electronically at SciTech Connect http:/www.osti.gov/scitech

Available for a processing fee to U.S. Department of Energy and its contractors, in paper, from:

U.S. Department of Energy

Office of Scientific and Technical Information

P.O. Box 62

Oak Ridge, TN 37831-0062

OSTI http://www.osti.gov

Phone: 865.576.8401

Fax: 865.576.5728

Email: reports@osti.gov

Available for sale to the public, in paper, from:

U.S. Department of Commerce

National Technical Information Service

5301 Shawnee Road

Alexandria, VA 22312

NTIS http://www.ntis.gov

Phone: 800.553 .6847 or 703.605 .6000

Fax: 703.605.6900

Email: orders@ntis.gov 


\section{Acknowledgments}

This work was supported by the U.S. Department of Energy (DOE) under Contract No. DEAC36-08GO28308 with the National Renewable Energy Laboratory. Funding for the work was provided by the DOE Office of Energy Efficiency and Renewable Energy, Wind Energy Technologies Office. 


$\begin{array}{ll}\text { List of Acronyms } \\ \text { CRB } & \begin{array}{l}\text { cylindrical roller bearing } \\ \text { GRC }\end{array} \\ \mathrm{kN} & \text { kearbox Reliability Collaborative } \\ \mathrm{kNm} & \text { kilonewton meter } \\ \mathrm{kW} & \text { kilowatt } \\ \mathrm{NREL} & \text { National Renewable Energy Laboratory } \\ \text { TDC } & \text { top dead center } \\ \text { TRB } & \text { tapered roller bearing }\end{array}$

iv

This report is available at no cost from the National Renewable Energy Laboratory at www.nrel.gov/publications. 


\section{Table of Contents}

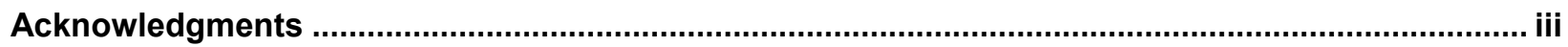

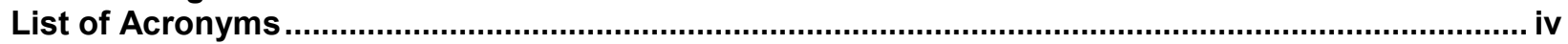

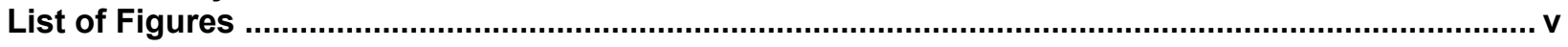

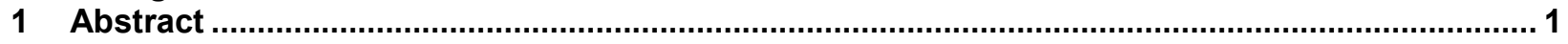

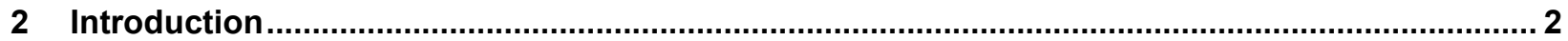

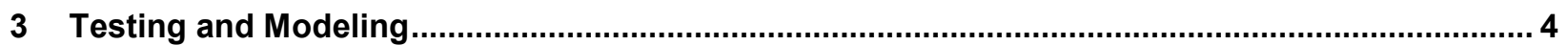

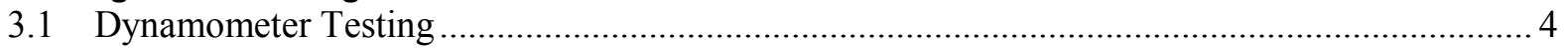

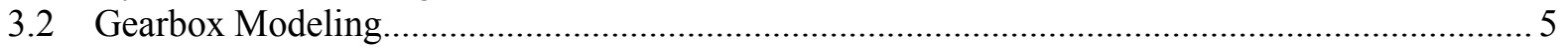

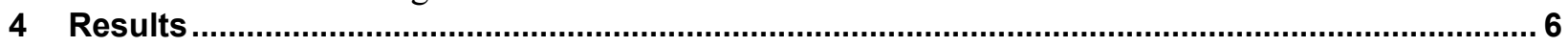

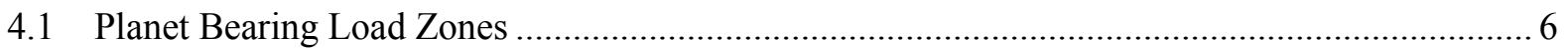

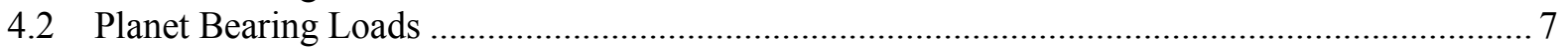

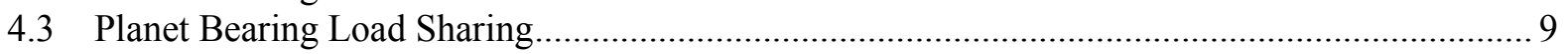

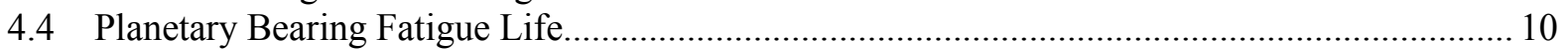

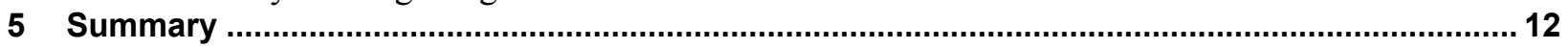

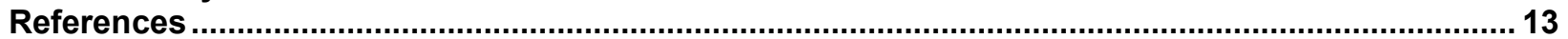

\section{List of Figures}

Figure 1. Comparison of the original GB1 and GB2 (left) and the new GB3 (right) design characteristics. Illustration by Romax Technology (right)....................................................... 2

Figure 2. GB1 and GB2 planet cylindrical roller bearing measurement locations............................ 4 Figure 3. GB3 planet tapered roller bearing measurement locations. Illustration by the Timken Company

Figure 4. Planet bearing load zones for GB2 with $-300 \mathrm{kNm}$ (left), pure torque (middle), and +300

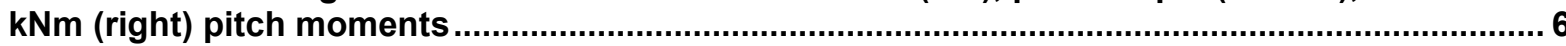

Figure 5. Planet bearing load zones for GB3 with $-300 \mathrm{kNm}$ (left), pure torque (middle), and +300 kNm (right) pitch moments

Figure 6. Planet bearing loads in pure torque for GB2 (left) and GB3 (right) .................................. 8

Figure 7. Planet bearing loads with $-300 \mathrm{kNm}$ pitch moment for GB2 (left) and GB3 (right) ............. 8

Figure 8. Upwind (left) and downwind (right) measured planet bearing loads for GB2 ................... 9

Figure 9. Maximum planet bearing loads for pitch moments for GB2 (left) and GB3 (right) ........... 10

Figure 10. Maximum planet bearing loads for yaw moments for GB2 (left) and GB3 (right) ............ 10

Figure 11. Fatigue life for the planet bearings (left) and planetary bearing stage (right)................. 11 


\section{Abstract}

This work compares the planetary load-sharing characteristics of wind turbine gearboxes supported by cylindrical roller bearings (CRBs) and preloaded tapered roller bearings (TRBs) when subjected to rotor moments. Planetary bearing loads were measured in field-representative dynamometer tests and compared to loads predicted by finite-element models. Preloaded TRBs significantly improved load sharing. In pure torque conditions, the upwind planet bearing load in the gearbox with preloaded TRBs was only $14 \%$ more than the assumed load compared to $47 \%$ more for the gearbox with CRBs. Consequently, the predicted fatigue life of the complete set of planetary bearings for the gearbox with preloaded TRBs is 3.5 times greater than that of the gearbox with CRBs. 


\section{Introduction}

Wind turbine gearboxes operate in a challenging environment [1]. Many do not achieve their expected design life [2]; however, they commonly meet or exceed the criteria specified in gear, bearing, and wind turbine industry standards as well as third-party certifications. The cost of gearbox replacements and rebuilds and the downtime associated with these failures increase the cost of wind energy. In 2007, the U.S. Department of Energy established the National Renewable Energy Laboratory (NREL) Gearbox Reliability Collaborative (GRC). Its goals are to understand the root causes of premature gearbox failures and improve their reliability.

The GRC uses a combined gearbox testing, modeling, and analysis approach. To date, it has focused on a 750-kilowatt (kW) drivetrain with a three-stage, three-point mounted gearbox. A nonproprietary version of the gearbox containing CRBs with $\mathrm{C} 3$ clearances in the planetary stage was purpose-designed. Two of these gearboxes, Gearbox 1 (GB1) and Gearbox 2 (GB2), were manufactured and then field- and dynamometer-tested [3]. Each included extensive instrumentation focusing primarily on planetary stage load-sharing characteristics.

Major GRC findings include the detrimental effect of rotor moments on planetary load sharing and predicted fatigue and the risk of bearing sliding in low-torque conditions for three-point configuration drivetrains [4-7]. All of the GRC's engineering drawings, models, and test data are publicly available $[8,9]$.

Based on the knowledge gained from testing and analysis of the original design, the GRC gearbox was redesigned to improve its load-sharing characteristics and predicted fatigue while still using the original housing and planet carrier. This new gearbox is named Gearbox 3 (GB3); as shown in Figure 1, its key improvement is the incorporation of preloaded TRBs that support the planet carrier and planets.
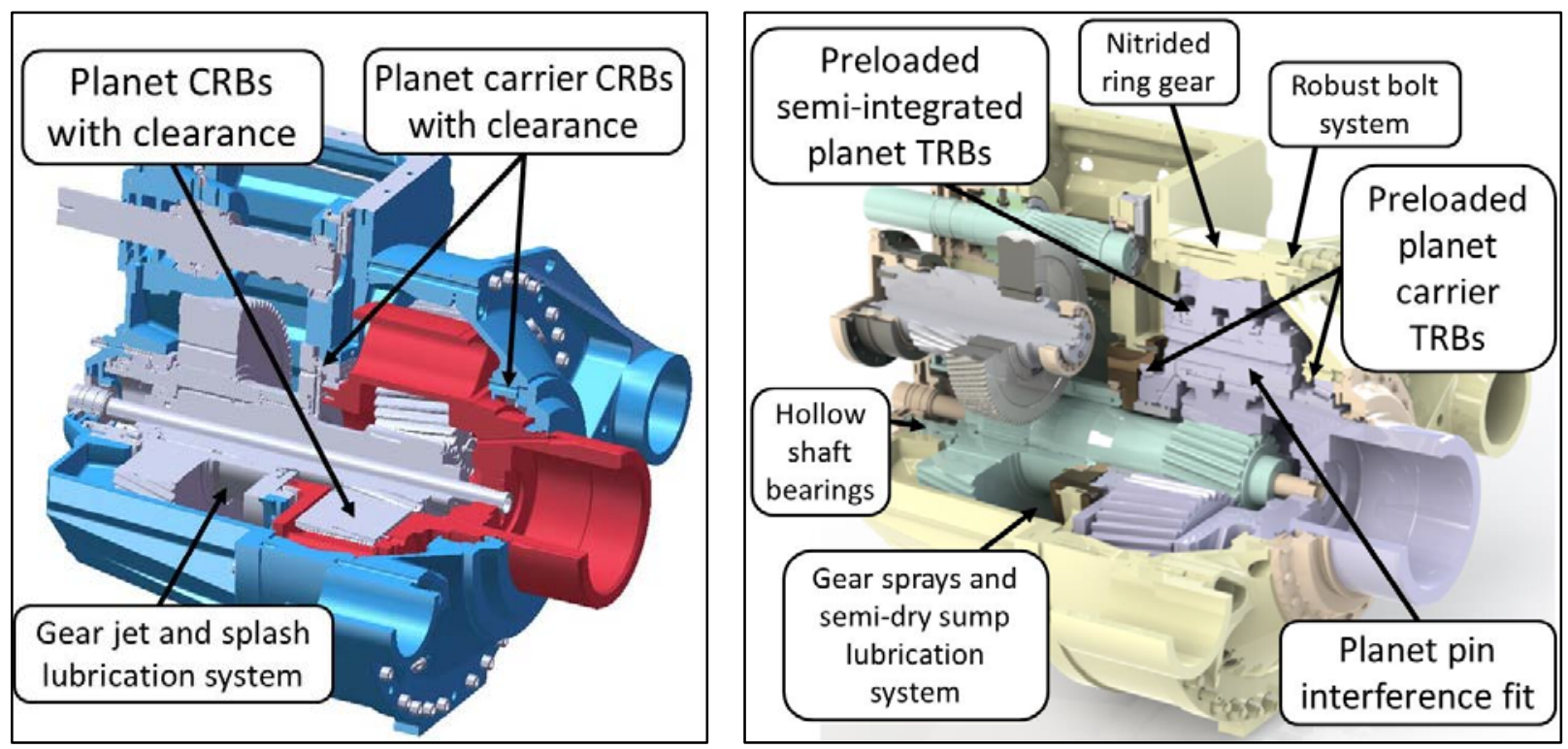

Figure 1. Comparison of the original GB1 and GB2 (left) and the new GB3 (right) design characteristics. Illustration by Romax Technology (right) 
A small preload (creating a small negative operating clearance) can optimize roller loads and maximize bearing life [10]. These preloaded bearings, along with interference-fitted planet pins, improve planet alignments and load-sharing characteristics. A semi-integrated planet bearing design in GB3 also increases capacity and eliminates outer race fretting.

GB3 is projected to have three times the planetary stage L10 life compared to the original gearbox, similar to the projected increase in fatigue life in other applications [11,12]. Romax Technology, with Powertrain Engineers and The Timken Company (Timken), completed the redesign. Timken manufactured and instrumented the planet gears and bearings. Brad Foote Gearing manufactured the other gearing and assembled the gearbox. 


\section{Testing and Modeling}

The drivetrain operates in a stall-controlled, three-bladed upwind turbine with a rated power of $750 \mathrm{~kW}$. It generates electricity at two speeds, in which the gearbox ratio of 81.491 converts the rotor speed to $1,200 \mathrm{rpm}$ or $1,800 \mathrm{rpm}$ generator speed [3]. The drivetrain configuration is a conventional three-point suspension commonly used in the industry. Both versions of the GRC gearbox design are composed of one low-speed planetary stage with three planet gears and a floating sun with $7.5^{\circ}$ helical gearing, plus two parallel stages with $14^{\circ}$ helical gearing. GB1 and GB2 planet bearings are commercially available NJ2232EM1C3, while for GB3 they are custom bearings of Timken designation NP527934 with 150 micrometer $(\mu \mathrm{m})$ nominal, mounted preload [9].

\subsection{Dynamometer Testing}

The gearboxes were tested in the National Wind Technology Center's 2.5-megawatt dynamometer $[8,9]$. Constant torque and speed tests were conducted in offline, $10 \%, 20 \%, 50 \%$, $75 \%$, and $100 \%$ power conditions (350 kilonewton meter $(\mathrm{kNm})$ torque) with rotor moments ranging between $\pm 300 \mathrm{kNm}$ based on field tests [3]. Additional dynamic torque and rotor moments representing several wind speeds, misaligned generator, drivetrain shutdown, and grid loss tests were also conducted.

Each GRC gearbox has 36 strain-gauge pair measurements of planet bearing loads evenly split between the upwind and downwind bearings, with the majority located in the expected load zones. The nearly identical helical gearing in each gearbox causes an overturning moment on the planets, resulting in a $\pm 20^{\circ}$ offset of the center of each load zone from the bearing top dead center (TDC). Figure 2 and Figure 3 show the expected load zones and measurement locations for each gearbox. The GB1 and GB2 measurements were made at identical circumferential locations for each bearing. Two measurements were taken along the bearing inner-race width to investigate the axial load distribution between the upwind and downwind bearing rows [3].

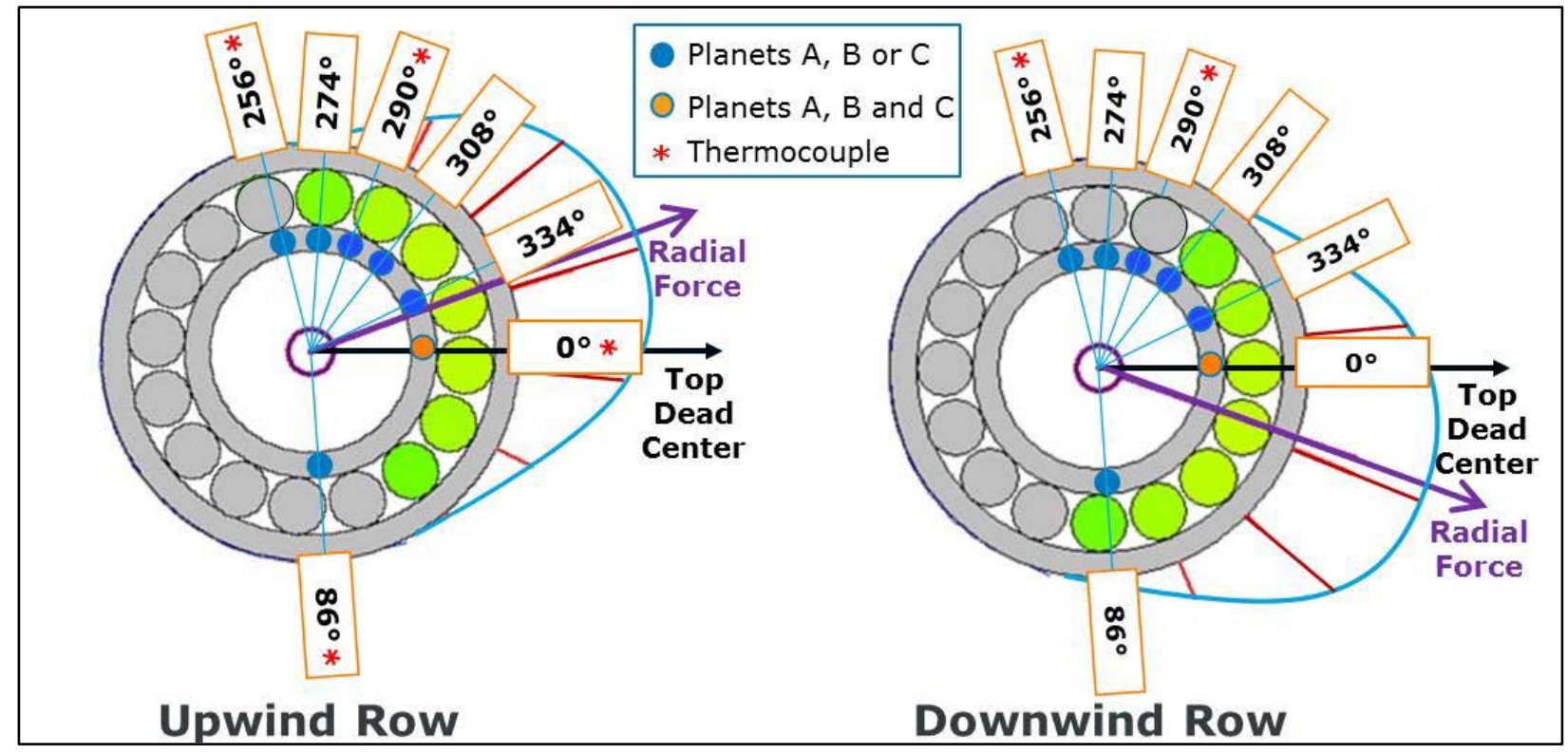

Figure 2. GB1 and GB2 planet cylindrical roller bearing measurement locations 
The GB3 measurements focused on the circumferential load distribution, with only one axial measurement on each bearing inner race. As shown in Figure 3, one planet (B) has measurements at 10 circumferential locations per bearing row, nine of which span the expected load zone. The other two planets have measurements at four circumferential locations per bearing row [9]. Several thermocouples were also installed on the bearings.

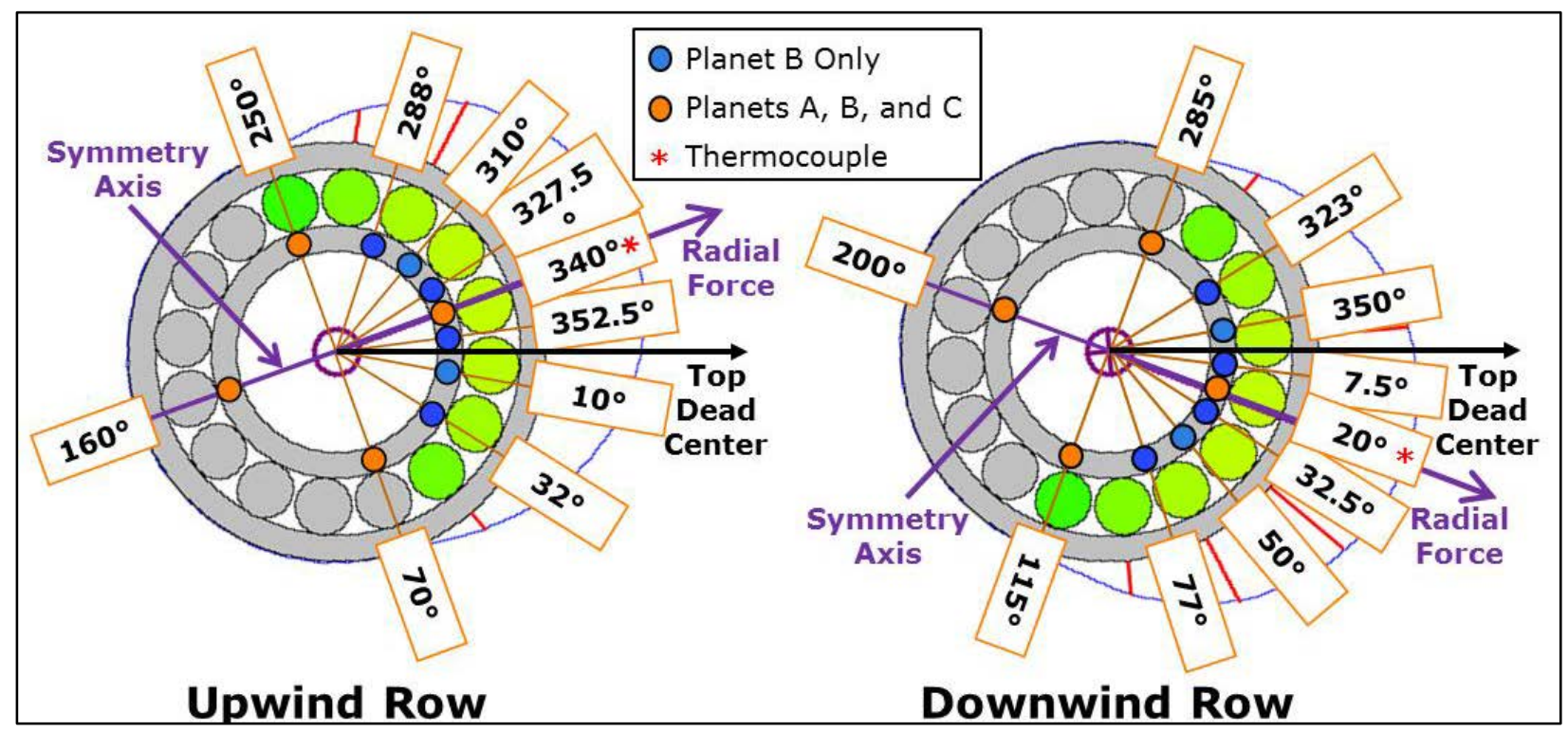

Figure 3. GB3 planet tapered roller bearing measurement locations. Illustration by The Timken Company

\subsection{Gearbox Modeling}

A three-dimensional, finite-element, contact-mechanics model in Advanced Numerical Solution's Transmission3D software was used to predict planetary loads for each gearbox [13]. In Transmission3D, the entire drivetrain is represented as deformable bodies, computing gear, and bearing contacts, including clearance nonlinearities with a hybrid of finite elements to predict far-field displacements and a Green's function model to predict displacements in the contact region. Known bearing clearances, preload, and pin position errors were included.

Bearing fatigue life calculations were made in RomaxWind, a product development and simulation software for the design and analysis of wind turbine gearboxes, bearings, and drivetrains [14]. The model includes beam-finite element representation of shafts and solid-finite element representation of the gearbox housing, gear blanks, planet carrier, and torque arms. The gears and bearings were modeled with semianalytical formulations that account for misalignment, area of contact under load, microgeometry, radial and axial clearances, and material properties. Static nonlinear analysis was performed for prescribed loading conditions, and the global deflections were solved simultaneously with the contact mechanics for the gears and bearings. 


\section{Results}

In this section, the planetary bearing loads predicted by the model and measured in dynamometer tests are compared only for the constant, full-power cases. The roller load at each measurement location is first determined by converting the average strain range with calibration factors determined from dedicated bench tests $[15,16]$. For GB1 and GB2, a direct-calibration factor is then used to determine the total bearing load [17] from only the TDC measurement, whereas for GB3 the entire load zone is mapped and a spline fit is then used to estimate the total bearing load. The predicted fatigue lives of both planetary designs were also calculated and compared.

\subsection{Planet Bearing Load Zones}

Figure 4 and Figure 5 compare the bearing load zones for each gearbox in the constant, fullpower condition when the planet is at the bottom of the ring gear. The load zones for the pure torque condition are compared to those for extreme positive and negative pitch moments. For GB2, shown in Figure, the upwind bearing load zone increases in size as the applied pitch moment increases. In general, the upwind planet bearing also supports much more load than the downwind bearing - in some situations twice as much. This phenomenon is caused by gear misalignment due to the $\mathrm{C} 3$ clearances in the planet and carrier bearings. The downwind planet bearing load zone is not significantly affected by the applied pitch moment. The theoretical maximum roller load of approximately 45 kilonewton $(\mathrm{kN})$ for each bearing [17] correlates with the measurements and predictions.
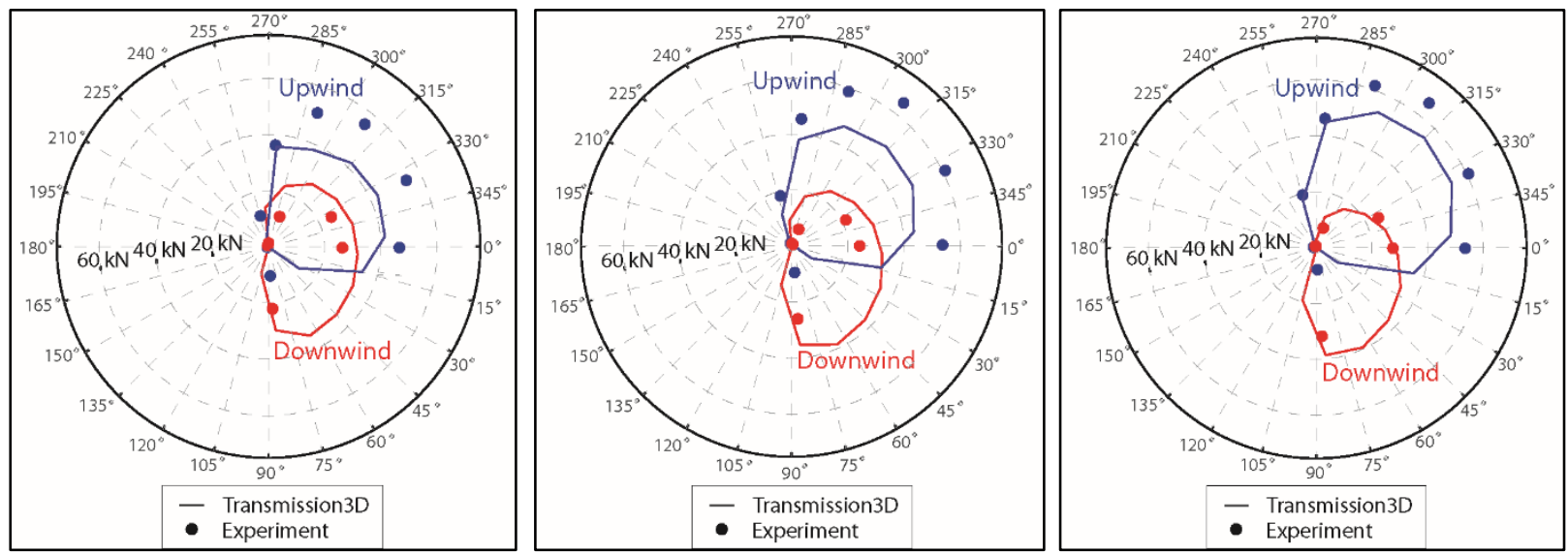

Figure 4. Planet bearing load zones for GB2 with $-300 \mathrm{kNm}$ (left), pure torque (middle), and +300 kNm (right) pitch moments

In contrast, as shown in Figure, the load zones for GB3 maintain their size and orientation regardless of the applied pitch moment. The more circular shape of the load zones reflects the preload in the bearings and the rigidity of the planetary system in general. The measured load zone magnitudes and orientations correlate well with the predictions, including the $\pm 20^{\circ}$ offset of the load zone from TDC shown in Figure. The theoretical maximum roller load, also approximately $45 \mathrm{kN}[16,17]$, again correlates with the measurements and predictions. 

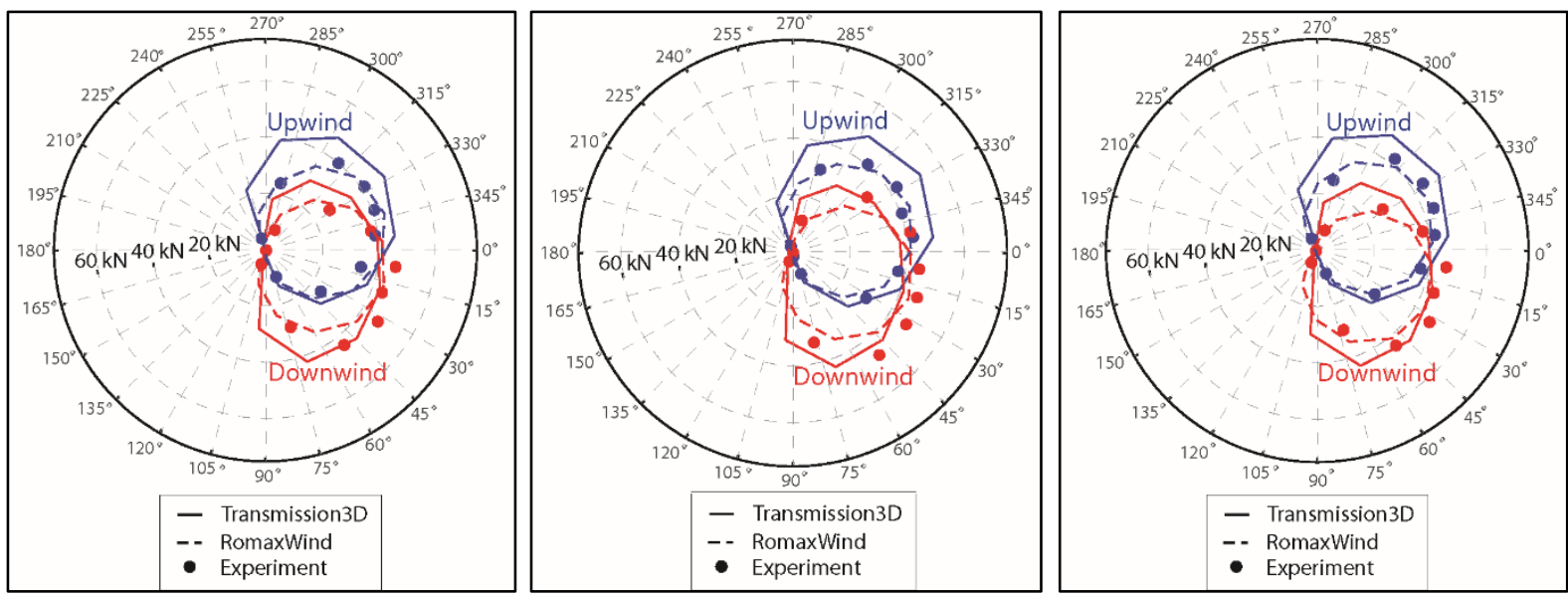

Figure 5. Planet bearing load zones for GB3 with $-300 \mathrm{kNm}$ (left), pure torque (middle), and +300 kNm (right) pitch moments

\subsection{Planet Bearing Loads}

The upwind and downwind bearing loads can be calculated from the load zones throughout the carrier rotation. The total load supported by both bearings, which is the vector summation of the upwind and downwind bearing loads, can also be calculated. Figure 6 compares these loadsnondimensionalized by the assumed load (i.e., one-sixth or one-third the load at the planet center resulting from input torque) - over a complete main shaft and carrier rotation in the full-power, pure torque condition. For GB2, the bearing loads fluctuate over the rotation and are also out of phase because of planet- and carrier- bearing clearances and planet pin compliance [6]. The maximum load carried by the upwind bearing is $43 \%$ more than the assumed load, and the minimum load carried by the downwind bearing is $39 \%$ less than the assumed load.

In this condition, the upwind bearing is accumulating more fatigue than expected; conversely, the downwind bearing has an increased risk of skidding. But because they are nearly $180^{\circ}$ out of phase, there is much less fluctuation in the total load than the individual row loads. The maximum total bearing load is only $6 \%$ greater than assumed. The bearing loads for GB3 fluctuate in a manner similar to those of GB2, but with much less amplitude and more in phase due to the preload in the bearings and the interference-fitted planet pins. The maximum and minimum row loads are $11 \%$ different than assumed, whereas the maximum total bearing load is only $1 \%$ more than assumed. 

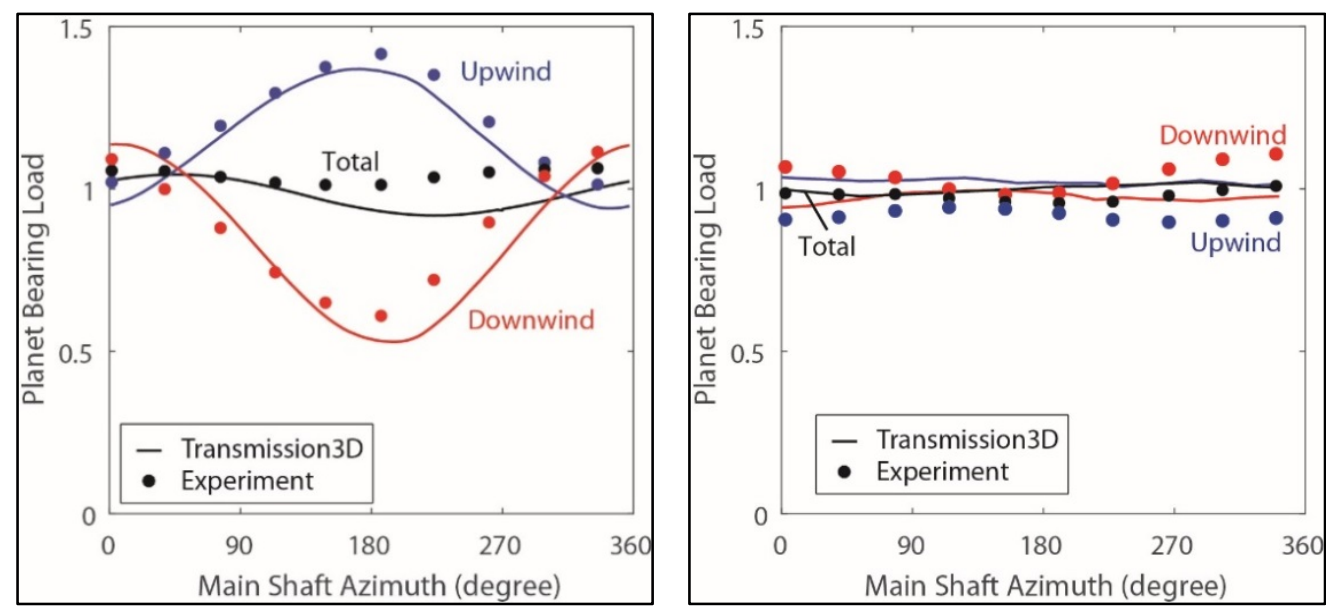

Figure 6. Planet bearing loads in pure torque for GB2 (left) and GB3 (right)

In contrast, Figure 7 compares the loads with an extreme negative pitch moment. For GB2, the upwind load is relatively constant but $25 \%$ greater than assumed. The downwind load behavior is very similar to pure torque, with a minimum load 30\% less than assumed. The net effect is that the total bearing load fluctuates slightly more than the pure torque condition and $15 \%$ more than assumed. For GB3, the loads again fluctuate very little - only $11 \%$ for the downwind row and $2 \%$ for the total bearing load.
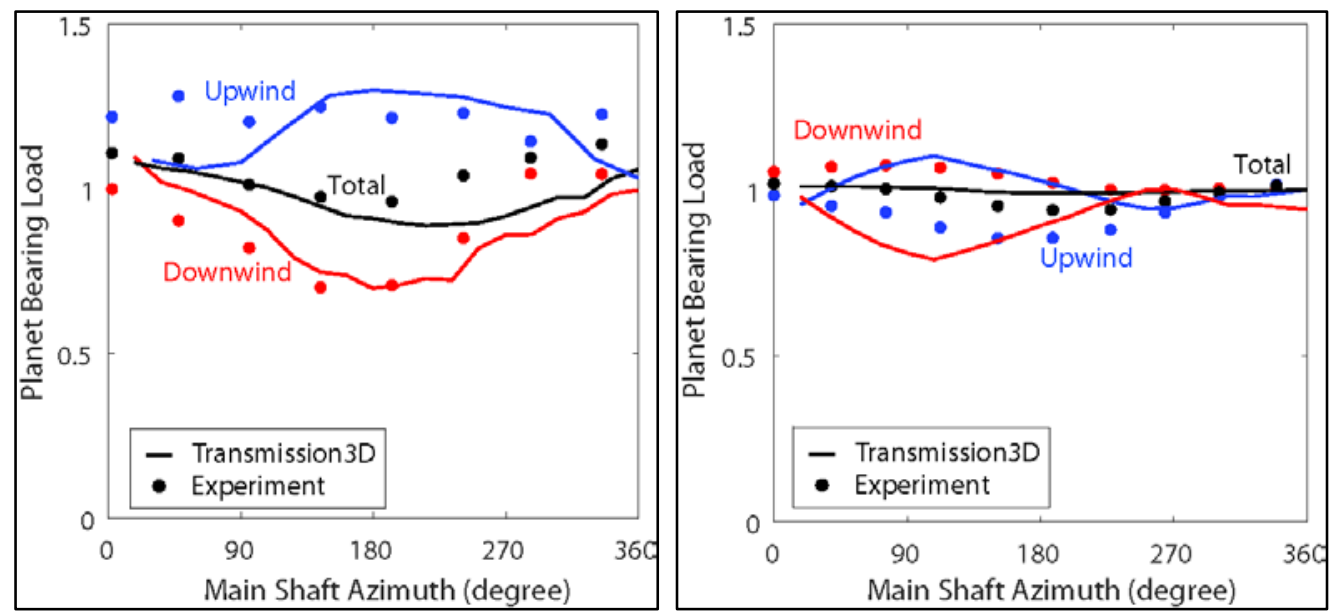

Figure 7. Planet bearing loads with $-300 \mathrm{kNm}$ pitch moments for GB2 (left) and GB3 (right)

Figure 8 summarizes the measured upwind and downwind planet bearing loads for GB2 in all the pitch moment cases. The behavior of the upwind bearing loads can be separated into three categories. Pure torque and positive pitch moment conditions all essentially have the same effect, resulting in the largest variation over the carrier rotation and overall magnitude in the bearing load. Large negative pitch moments somewhat elevate the bearing load, but do so relatively constantly over the carrier rotation. The $-100 \mathrm{kNm}$ pitch moment case is a transition between these two categories. Increasing the pitch moment beyond these bounds (pure torque and -200 $\mathrm{kNm}$ ) does not alter the upwind-bearing load. Any additional pitch moment is most likely reacted by the carrier bearings instead of the planet bearings. In between the two bounds, the pitch moment relieves the gravity load resulting from the weight of the main shaft and planetary 
system. Regardless of the pitch moment, the downwind bearing loads do not change significantly.
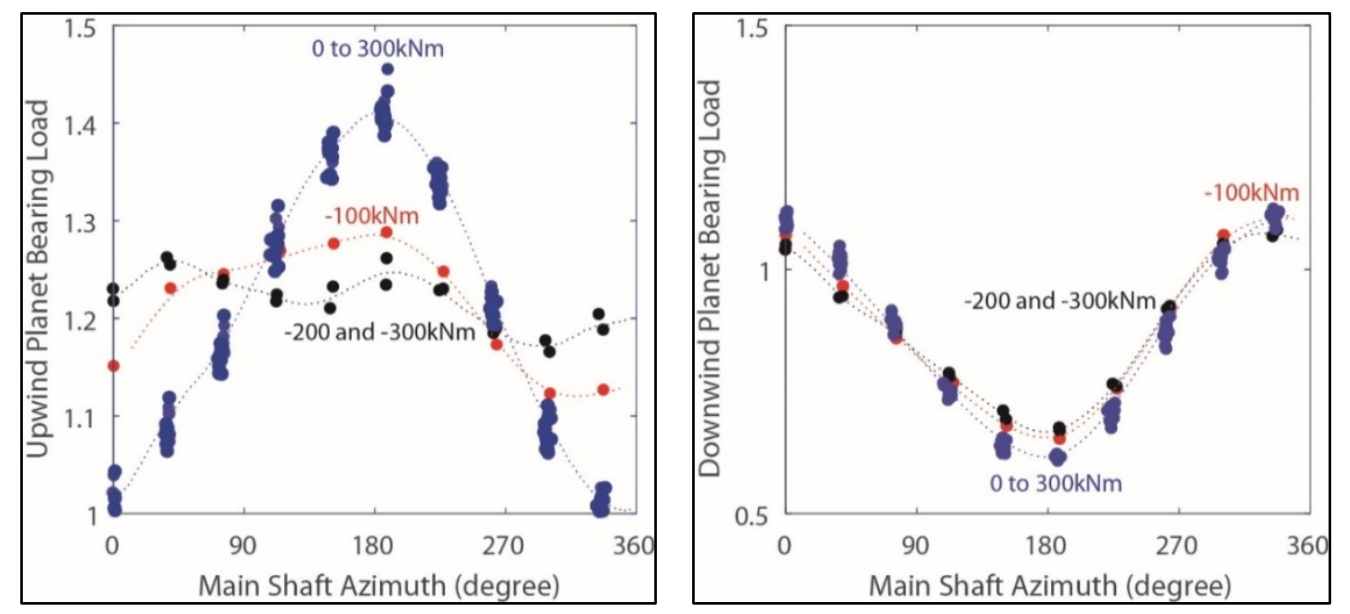

Figure 8. Upwind (left) and downwind (right) measured planet bearing loads for GB2

The bearing loads shown in these figures contain both a constant difference from the assumed load and a fluctuating component. The loads clearly are not equally shared in practice. The constant difference is a result of deformations, displacements, and manufacturing deviations causing consistently higher loads on one planet than the others [18]. Conversely, the fluctuating component is a result of the rotor moments and gravity, exacerbated by planet- and carrierbearing clearances, causing a once-per-revolution load variation over the carrier rotation $[5,7]$.

\subsection{Planet Bearing Load Sharing}

The accurate estimation of planet bearing loads is a crucial step in calculating the planetary loadsharing factor, also called the planetary mesh load factor $(\mathrm{K} \gamma)$. Ideally, all planets share torque equally and the planetary mesh load factor equals 1 . As a result of positional-type errors and variations in tooth stiffness, the load factor is assumed in International Electrotechnical Commission standard 61400-4 to be 1.1 for three-planet wind turbine gearboxes. In this study, the maximum load throughout the main shaft rotation as shown in Figure 6, Figure 7, and Figure 8 , which accounts for both constant load differences and the fluctuating load from gravity and rotor moments, is examined for comparison to this assumption.

Figure 9 compares the maximum individual bearing row load and maximum total bearing load for both gearboxes at full power over the complete range of rotor pitch moments tested. For GB2, the maximum total bearing load ranges from 1.08 at pure torque to just over 1.15 for large negative pitch moments. However, the load carried by the upwind bearing reaches as high as 1.47. Counterintuitively, the maximum value occurs in the pure torque condition and remains high with positive pitch moments as shown previously in Figure 8. The downwind bearing load does not exceed 1.12. Multiple acquisitions were made in pure torque conditions, and the data shows good repeatability. For GB3, the maximum total bearing load ranges from 1.02 at pure torque to 1.08 for an extreme negative pitch moment. The maximum load of the upwind bearing row is 1.14 in pure toque and no more than 1.17 for an extreme positive pitch moment - much lower than GB2. A significant reduction of the maximum loads and improvement in load sharing was achieved with the GB3 design changes. Many more data acquisitions were made for GB3 
than for GB2. In addition, these acquisitions were made after applying different rotor moments and then returning to the desired condition over several hours of dynamometer testing. The repeatability of the data is very good.
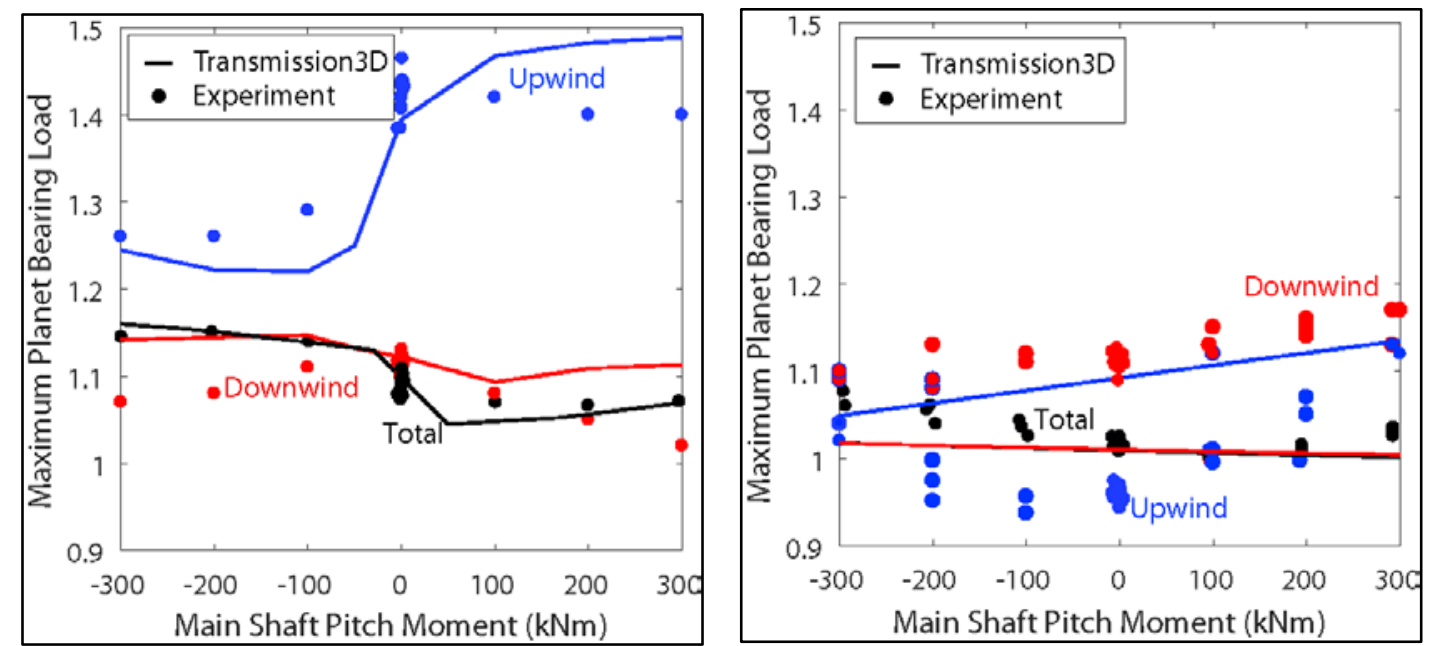

Figure 9. Maximum planet bearing loads for pitch moments for GB2 (left) and GB3 (right)

For comparison, Figure 10 shows the same loads over the full range of rotor yaw moments. The maximum upwind bearing load of 1.47 again occurs in pure torque conditions for GB2. Yaw moments, however, do not significantly change the maximum upwind bearing load. It remains above 1.33 regardless of the yaw moment, which supports the assertion that this load is primarily a result of gravity. The total bearing load follows a more intuitive pattern, in which it achieves a minimum of 1.08 at pure torque and increases slighty to 1.13 with either positive or negative yaw moments. Similar to pitch moments, yaw moments have little effect on the GB3 bearing loads. The maximum load of 1.13 occurs for the downwind bearing for a positive yaw moment.
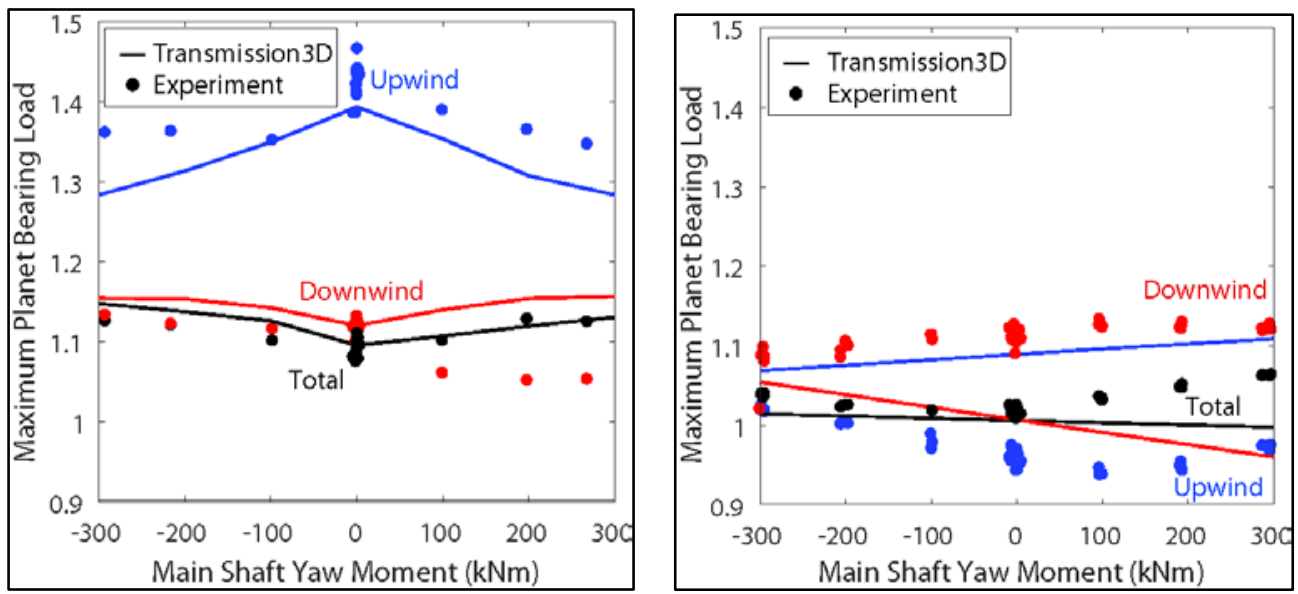

Figure 10. Maximum planet bearing loads for yaw moments for GB2 (left) and GB3 (right)

\subsection{Planetary Bearing Fatigue Life}

RomaxWind was used to calculate the predicted planetary fatigue life for a predetermined drivetrain torque and rotor moment spectrum [19]. Modified L10 life was calculated per Deutsches Institut für Normung International Organization for Standardization 281 Beiblatt 4 
(superseded by International Organization for Standardization technical specification 16281), including a systems life modification factor. As shown in Figure, the predicted fatigue life of the upwind bearing was significantly increased in GB3, in addition to a smaller life extension in both bearings due to the larger bearing capacity in the semi-integrated design. The predicted $\mathrm{L} 10 \mathrm{~m}$ life for the 8 planetary bearings as a whole ( 6 planet bearings and 2 carrier bearings), combined using a Weibull slope of 1.125 [20], is also shown. The planetary bearing stage predicted fatigue life has been increased by a factor of 3.5, from 3.4 years for GB1 and GB2 to 11.9 years for GB3. The planetary bearing stage life is driven by the lowest-life components, which in this case are the planetary bearings in both gearboxes.
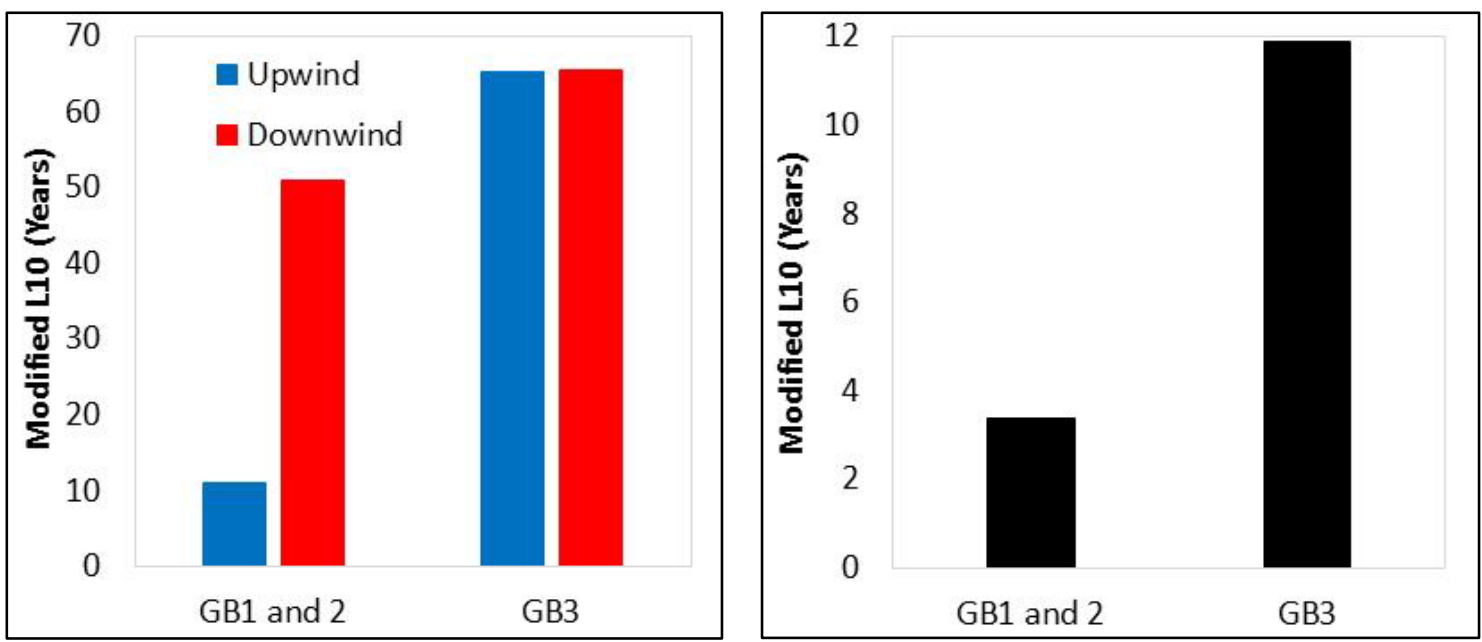

Figure 11. Fatigue life for the planet bearings (left) and planetary bearing stage (right) 


\section{Summary}

This study compared two wind turbine gearbox designs, including a conventional design representing the majority of three-point suspension drivetrains and a new design tailored for improved gearbox reliability. These two designs differ in planetary carrier and planet bearings. The first design uses CRBs with clearance and the latter utilizes preloaded TRBs. Both gearboxes were instrumented and tested in controlled conditions in a dynamometer facility under the same set of loading conditions. The resulting planet bearing load measurements were correlated with predictions from full finite-element models of both gearboxes.

The gearbox design with preloaded TRBs demonstrated improved planetary load-sharing characteristics in the presence of rotor pitch and yaw moments. Compared to the gearbox with CRBs, preloaded TRBs significantly reduced the upwind planet bearing loads from a maximum of 1.47 to 1.14 in pure torque conditions. Furthermore, rotor moments did not significantly affect the upwind and downwind bearing row loads, and the difference between the row loads was also reduced. This reduction and equalization in loads, along with slightly larger capacity bearings as a result of the semi-integrated design, lead to a predicted L10m life 3.5 times greater for the gearbox with preloaded TRBs than for the gearbox with CRBs. 


\section{References}

1. Struggl, S., V. Berbyuk and H. Johansson. 2014. Review on wind turbines with focus on drive train system dynamics. Wind Energy, 18 (4): 567-90. doi: 10.1002/we.1721.

2. Sheng, S. 2013. Report on Wind Turbine Subsystem Reliability - A Survey of Various Databases. NREL/PR-5000-59111. National Renewable Energy Laboratory (NREL), Golden, CO (US). http://www.nrel.gov/docs/fy13osti/59111.pdf.

3. Link, H., W. LaCava, J. van Dam, B. McNiff, S. Sheng, R. Wallen, M. McDade, S. Lambert, S. Butterfield and F. Oyague. 2011. Gearbox Reliability Collaborative Project Report: Findings from Phase 1 and Phase 2 Testing (Technical Report). NREL/TP-5000-51885. National Renewable Energy Laboratory (NREL), Golden, CO (US). http://www.nrel.gov/docs/fy11osti/51885.pdf.

4. Crowther, A., V. Ramakrishnan, N.A. Zaidi and C. Halse. 2011. Sources of time-varying contact stress and misalignments in wind turbine planetary sets. Wind Energy, 14 (5): $637-$ 51. doi: 10.1002/we.447.

5. Guo, Y., J. Keller and W. LaCava. 2012. Combined Effects of Gravity, Bending Moment, Bearing Clearance, and Input Torque on Wind Turbine Planetary Gear Load Sharing: Preprint. NREL/CP-5000-55968. National Renewable Energy Laboratory (NREL), Golden, CO (US). http://www.nrel.gov/docs/fy12osti/55968.pdf.

6. LaCava, W., Y. Xing, C. Marks, Y. Guo and T. Moan. 2013. Three-dimensional bearing load share behaviour in the planetary stage of a wind turbine gearbox. IET Renewable Power Generation, 7 (4): 359-69. doi: 10.1049/iet-rpg.2012.0274.

7. Guo, Y., J. Keller and W. LaCava. 2014. Planetary gear load sharing of wind turbine drivetrains subjected to non-torque loads. Wind Energy, 18 (4): 757-68. doi: 10.1002/we.1731.

8. Keller, J. and R. Wallen. 2015. Gearbox Reliability Collaborative Phase 3 Gearbox 2 Test. NREL/TP-5000-63693. National Renewable Energy Laboratory (NREL), Golden, CO (US). doi: 10.7799/1254154. https://doi.org/10.7799/1254154.

9. Keller, J. and R. Wallen. 2017. Gearbox Reliability Collaborative Phase 3 Gearbox 3 Test. NREL/TP-5000-67612. National Renewable Energy Laboratory (NREL), Golden, CO (US). doi: 10.7799/1337868. https://doi.org/10.7799/1337868.

10. Oswald, F.B., E.V. Zaretsky and J.V. Poplawski. 2012. Effect of internal clearance on load distribution and life of radially loaded ball and roller bearings. Tribology Transactions, 55 (2): 245-65. doi: 10.1080/10402004.2011.639050.

11. Flamang, P. and P. Clement. 2003. Stresses and Load Distribution Factors in Bearings: A Tool to Compare Bearing Alternatives. Dresdner Maschinenelemente Kolloquium, 289-302. 
12. Lucas, D. Planet Pac: Increasing Epicyclic Power Density and Performance through Integration (AGMA 05FTM18). AGMA Fall Technical Meeting Proceedings, 2005.

13. Transmission3D. [Online]. Available: http://ansol.us/Products/TX3/

14. RomaxWind. [Online]. Available: http://www.romaxtech.com/software/romaxwind

15. J. van Dam. 2011. Gearbox Reliability Collaborative Bearing Calibration (Technical Report). NREL/TP-5000-47852. National Renewable Energy Laboratory (NREL), Golden, CO (US). http://www.nrel.gov/docs/fy12osti/47852.pdf.

16. Keller, J. and D. Lucas. 2017. Gearbox Reliability Collaborative Gearbox 3 Planet Bearing Calibration (Technical Report). NREL/TP-5000-67370. National Renewable Energy Laboratory (NREL), Golden, CO (US). http://www.nrel.gov/docs/fy17osti/67370.pdf.

17. T. Harris, and M. Kotzalas, Essential Concepts of Bearing Technology. Fifth Edition. Taylor \& Francis.

18. Cooley, C.G. and R.G. Parker. 2014. A review of planetary and epicyclic gear dynamics and vibrations research. Applied Mechanics Reviews, 66 (4): 040808-1-040804-15. doi: 10.1115/1.4027812.

19. A. Crowther. 2012. Design of a Wind Turbine Gearbox for Phase 3 of the Gearbox Reliability Collaborative, Romax Technology Report 1509-DC-001-B.

20. Zaretsky, E.V., D.G. Lewicki, M. Savage and B.L. Vleck. 2007. Determination of turboprop reduction gearbox system fatigue life and reliability. Tribology Transactions, 50 (4), 507-16. doi: $10.1080 / 10402000701613799$. 